\title{
Computer Model STAN 2000 and its Use in Practice of Steels Hot Rolling on Mill 2000 of Severstal
}

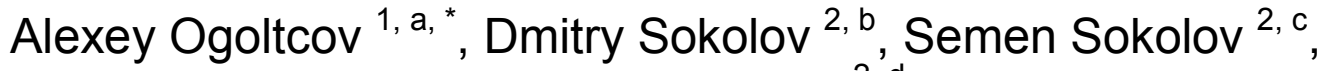 \\ Alexander Vasilyev ${ }^{2, d}$ \\ ${ }^{1}$ Severstal Russian Steel, 3 Mira Str., 162600 Cherepovets, Russia \\ ${ }^{2}$ Peter the Great St. Petersburg Polytechnic University, 29 Polytekhnicheskaya Str., 195251 St. \\ Petersburg, Russia
}

aAlexey.Ogoltsov@severstal.com, bsklv.d.f@gmail.com, c'sok_s_w@mail.ru, dvasilyev_aa@mail.ru

Keywords: Steels, hot rolling, microstructure, mechanical properties, modeling

Abstract. An integral computer model/program STAN 2000 for simulation of steels hot rolling on mill 2000 of SEVERSTAL was developed. The capacity of the model includes, for example, the following features:

- control of power parameters and prediction of hot strip temperature for a given rolling and accelerated cooling regimes;

- follow-up of the evolution of steel microstructure at all stages of strip production and prediction of ultimate mechanical properties (yield stress, ultimate tensile stress and relative elongation);

- optimization of rolling regimes for existing steel grades and developing them for a new ones.

The STAN 2000 program is written in $\mathrm{C}++$ programming language and can work on all modern Microsoft Windows family operating systems. The program has a well-designed and user-friendly interface facilitating its practical use.

The integral model was calibrated using an extensive data base on rolling regimes and forces, measured temperatures and final mechanical properties for a number of steel grades rolled on mill 2000 of SEVERSTAL with chemical compositions covering the following ranges of alloying elements content (mass.\%): $\mathrm{C}(\leq 0.65)$; $\mathrm{Mn}(\leq 2.0)$; $\mathrm{Si}(\leq 1.0) ; \mathrm{Cr}(\leq 0.9)$; $\mathrm{Ni}(\leq 0.6) ; \mathrm{Cu}(\leq 0.5)$; $\mathrm{Mo}(\leq 0.4) ; \mathrm{Nb}(\leq 0.05) ; \mathrm{V}(\leq 0.065) ; \mathrm{Ti}(\leq 0.06) ; \mathrm{B}(\leq 0.003)$.

Some results of calculations performed with STAN 2000 program for temperatures, rolling forces and mechanical properties are presented and compared with experimental data. Some examples of the program utilization in hot strip production on mill 2000 of SEVERSTAL are presented and discussed.

\section{Introduction}

In the last years considerable attention has been paid to the development of mathematical models for predicting the microstructure and mechanical properties of hot rolled steels. Since the appearance of the first such models $[1,2]$, there has been a need to develop more physically sound models for describing the complex processes of austenite microstructure evolution and transformation under hot rolling and accelerated cooling with formation of different structure components such as ferrite, pearlite, bainite and martensite. The benefit of these new models is better prediction capability of complex alloying effects on structure formation due to more physically accurate calculations of the thermodynamic and kinetic process parameters [3-5]. The developed sub-model for strip temperature prediction is an important model component that substantially improves the accuracy of steel microstructure prediction for a given hot rolling and accelerated cooling regimes.

In the present paper the developed integral computer model STAN 2000 is briefly described and some examples of its practical use for technology improvement and development are presented. 


\section{Brief Description of the Integral Model}

Computer model STAN 2000 is off-line model aimed at the improvement of rolling technology and its development for production of new products on rolling mill 2000 of SEVERSTAL (Fig. 1). The model includes the following features:

- control of energy and power parameters;

- control of temperature depending on selected rolling and accelerated cooling regimes;

- follow-up of the steel microstructure evolution at all stages of strip production;

- prediction of ultimate mechanical properties.

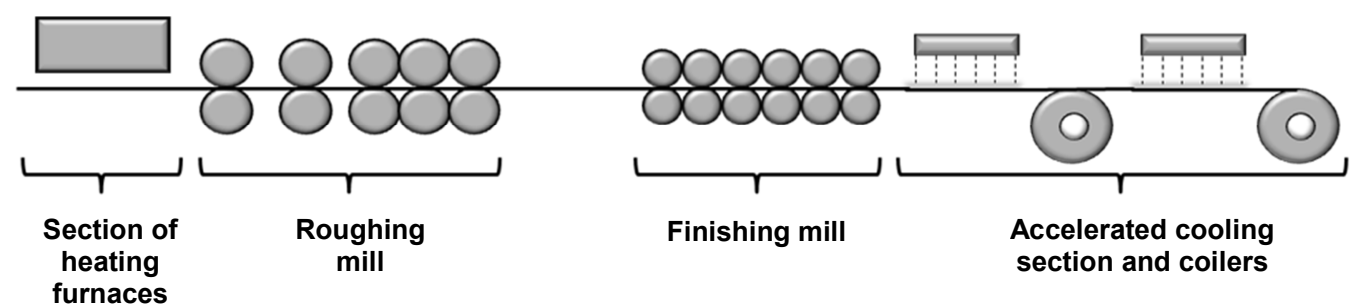

Fig. 1. Layout of the equipment of rolling mill 2000

The integral model under consideration includes a set of sub-models described in [3-6]. In this section a brief description of the sub-models is given and some results of calculations performed for the steel Grade \#1 (0.11 C; $1.54 \mathrm{Mn} ; 0.31 \mathrm{Si} ; 0.12 \mathrm{Cr} ; 0.054 \mathrm{Nb} ; 0.024 \mathrm{~V})$ are presented.

\section{Temperature Model}

The temperature model is based on differential equations of heat conduction solved by the finite difference method, implemented in the program STAN 2000. It allows to calculate temperature distribution over the cross section of a rolled strip at any location along its length at the stages of roughing and finishing rolling, as well as under accelerated cooling on the run-out table.

The model takes into account the following mechanisms determining heat losses and generation at different rolling stages:

- heat loss as a result of a strip contact with work rolls;

- heat loss by radiation and convection;

- loss of heat by reacting with water at strip descaling, interstands cooling and laminar cooling;

- heating due to plastic deformation of the metal, scale growth and phase transformations under cooling.

Moreover, the temperature dependencies of thermodynamic parameters of steel are accounted for. The model was calibrated using a data base on strip surface temperatures measured by pyrometers of mill 2000. Some results of strip temperature calculation for the Grade \#1 steel are displayed in Fig. 2. From Fig. 3 can be seen that calculated and measured temperatures are in good quantitative agreement.

\section{Austenite Microstructure Evolution Model}

STAN 2000 program allows quantitative modeling of the austenite microstructure evolution during hot rolling of modern HSLA steels including steels micro-alloyed with niobium, vanadium and titanium. The program implements an integral mathematical model of the following interrelated processes of steel structure evolution:

- grain growth;

- dynamic recrystallization; 
- static recrystallization providing for the effects of recovery and micro-alloying elements carbonitrides precipitation on the dislocations of deformed austenite.

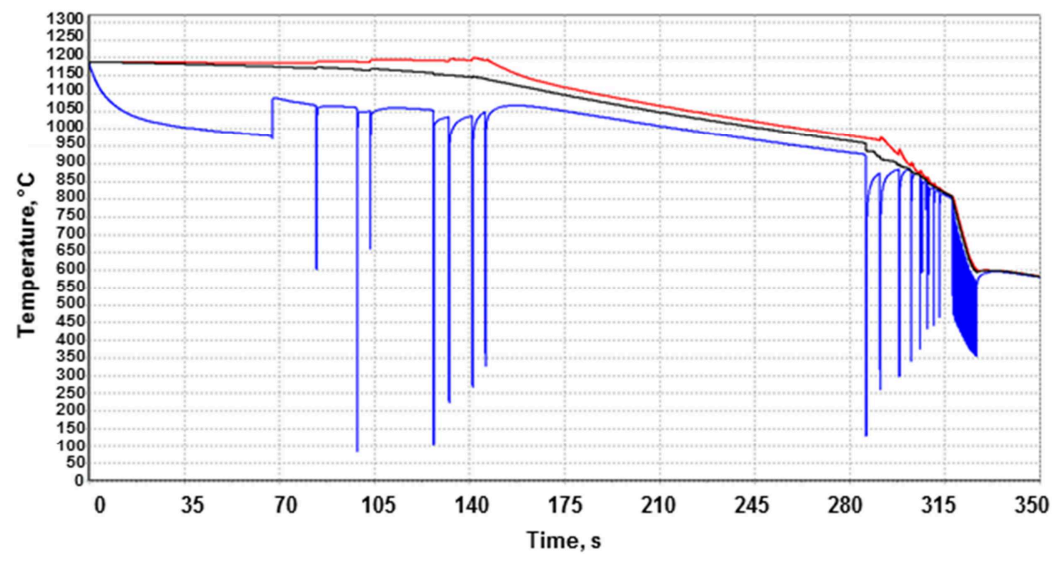

Fig. 2. Example of calculation results of temperature variation versus rolling time obtained using STAN 2000 program for Grade \#1 steel. Temperature curves for the strip surface (blue), middle (red) and average strip temperature (black).
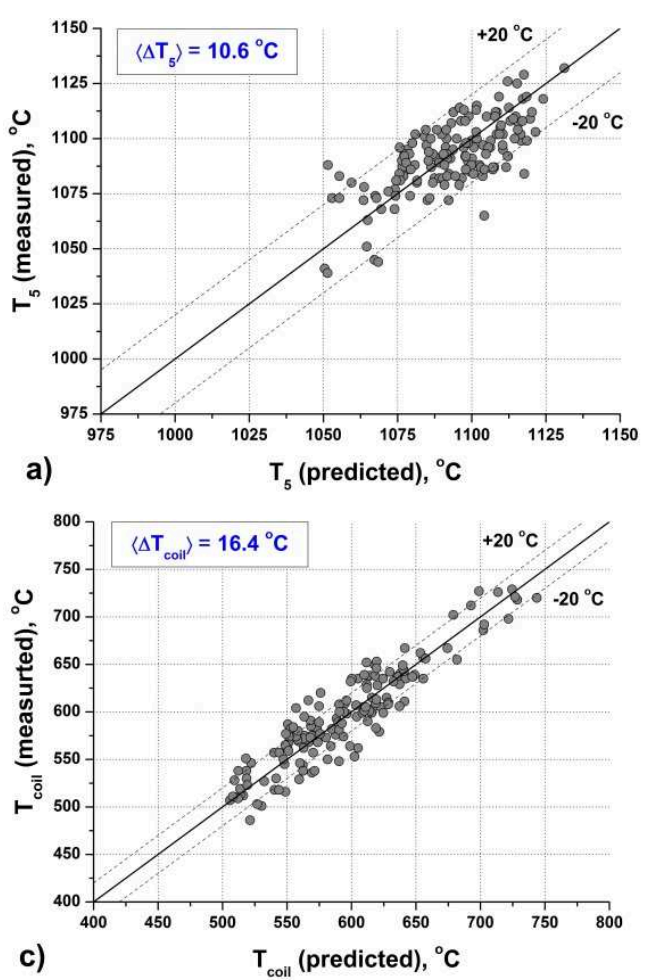

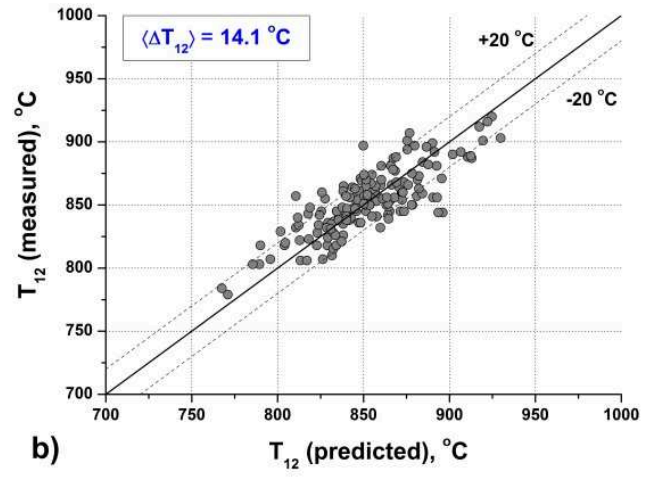

Fig. 3. Comparison of the predicted and measured surface temperatures for 164 strips rolled on mill 2000 of SEVERSTAL. $\mathrm{T}_{5}$ and $\mathrm{T}_{12}$ are the temperatures after the $5^{\text {th }}$ and $12^{\text {th }}$ stands of the roughing and finishing mills, accordingly; $\mathrm{T}_{\text {coil }}$ is a coiling temperature. $\langle\Delta \mathrm{T}\rangle$ is an average absolute value of prediction accuracy.

The mathematical models of the above-given processes of structuring were published elsewhere $[3,5]$. They are distinguished by a physically reasonable accounting for the effects of all practically important alloying elements. This feature makes the program effective for a large number of steel grades with a wide range of chemical composition variations.

Fig. 4 shows predicted variation in austenite grain size and retained strain over the strip width of Grade \#1 steel with time of rolling.

Austenite decomposition model describes this process under continuous cooling condition for low alloyed steels with formation of all practically important structural components (ferrite, pearlite, bainite of different morphology and martesite). Physically based mathematical models of ferrite, pearlite and bainite transformations are described in $[4,5]$. 


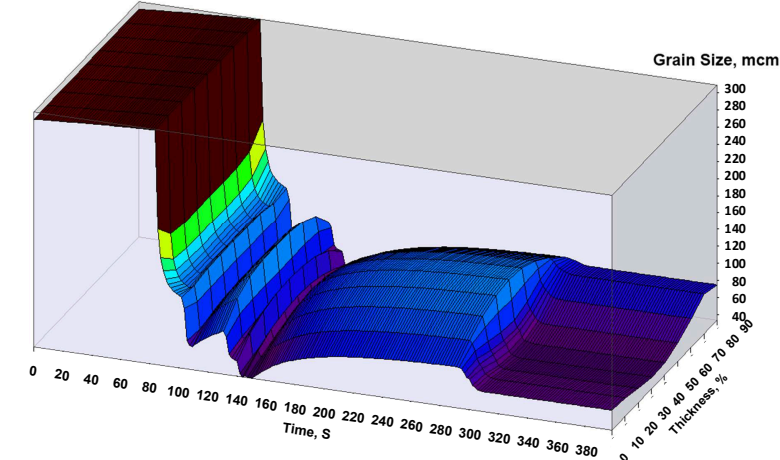

a)

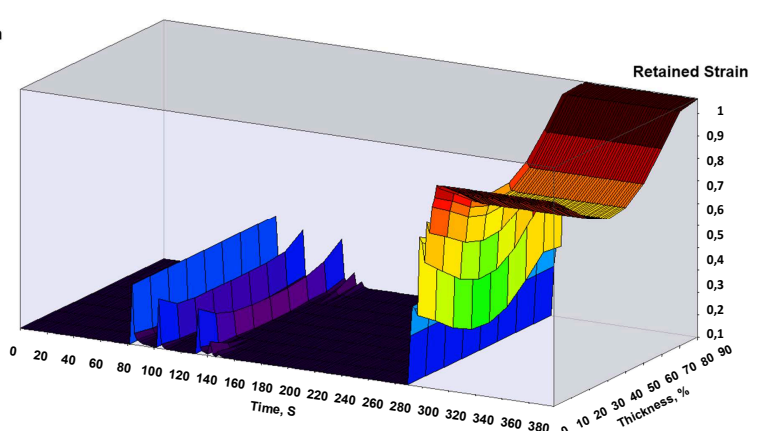

b)

Fig. 4. Predicted variation in austenite grain size (a) and retained strain (b) distributions over the strip width in Grade \#1 steel with time of rolling.

\section{Mechanical Properties Prediction Model}

This model predicts ultimate mechanical properties of steel basing on the calculated set of significant microstructure parameters: volume fractions of the structural components, the average ferrite grain and bainite block sizes, characteristic transformation temperatures, volume fractions and sizes of carbonitrides in micro-alloyed steels. The mathematical model for the mechanical properties evaluation in modern steels with a complex microstructure implemented in the present program is described elsewhere [6]. This model was calibrated using a mechanical properties data base for a number of practically important steels hot rolled on mill 2000 under different rolling regimes. A comparison of the predicted and measured values of mechanical properties for 31 steel grades shows a good agreement between calculation results and experimental data (Fig. 5).
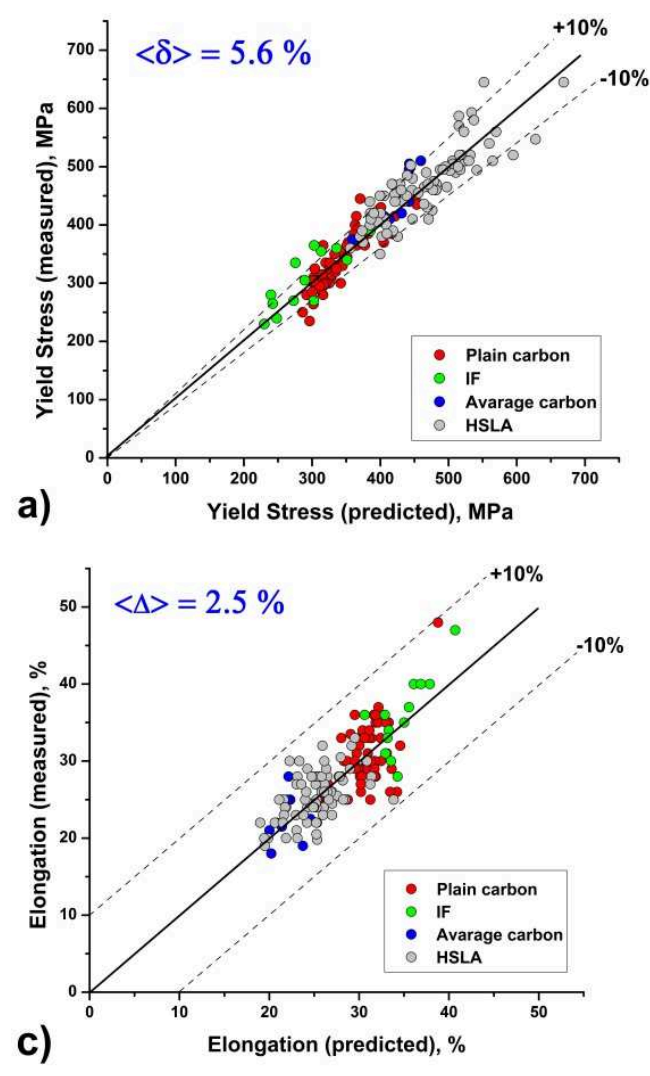

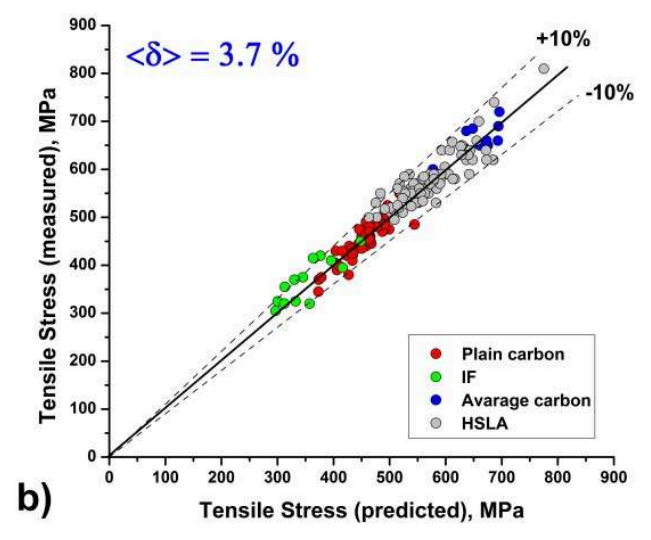

Fig. 5. Comparison of the calculated and measured values of yield stress (a), ultimate tensile stress (b) and relative elongation (c) for the steels hot rolled on mill 2000 of SEVERSTAL.

$\delta$ and $\Delta$ are, correspondently, average values of the relative and absolute accuracy.

\section{Practical Examples}

The model allows, for example, a quantitative simulation of different cooling strategy effects on final steel microstructure and mechanical properties. Utilization of the developed model STAN 
2000 has significantly reduced the time and costs for optimizing current rolling regimes, as well as accelerated cooling strategies aimed at production of strips with required properties (Fig. 6).
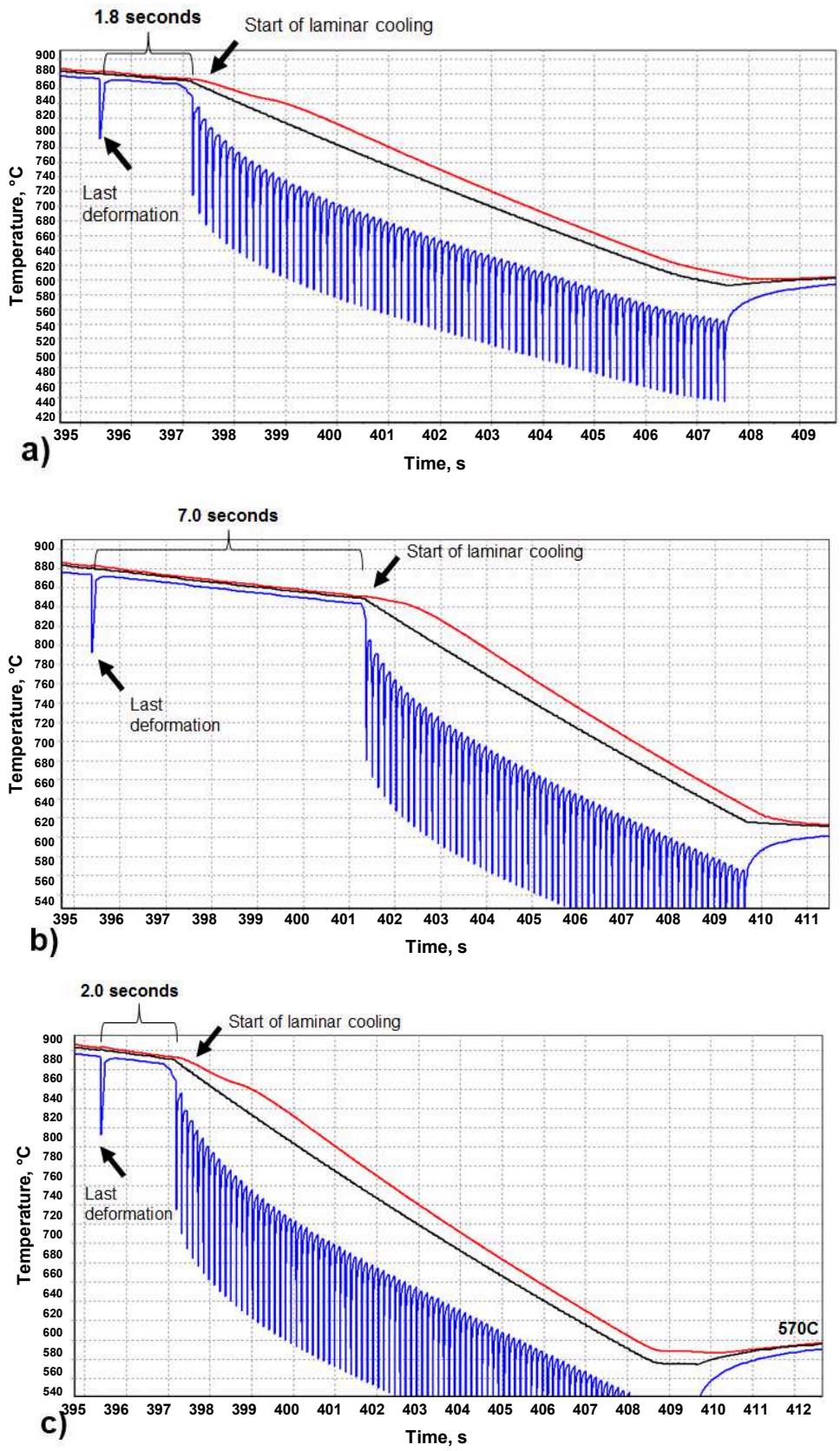

Fig. 6. Different strategies of accelerated cooling at run-out table. a) standard strategy: $\mathrm{YS}=510 \mathrm{MPa}$, UTS $=650 \mathrm{MPa}, \mathrm{RE}=25 \%$; b) long after deformation pause strategy: $\mathrm{YS}=450 \mathrm{MPa}$, UTS $=540 \mathrm{MPa}, \mathrm{RE}=23 \%$; c) fast cooling strategy: YS = 510MPa, $\mathrm{UTS}=620 \mathrm{MPa}, \mathrm{RE}=25 \%$.

Fig. 7 illustrates another example of successful application of the program for optimization of accelerated cooling regime for achieving consistently high level of plasticity with an acceptable level of strength properties. 

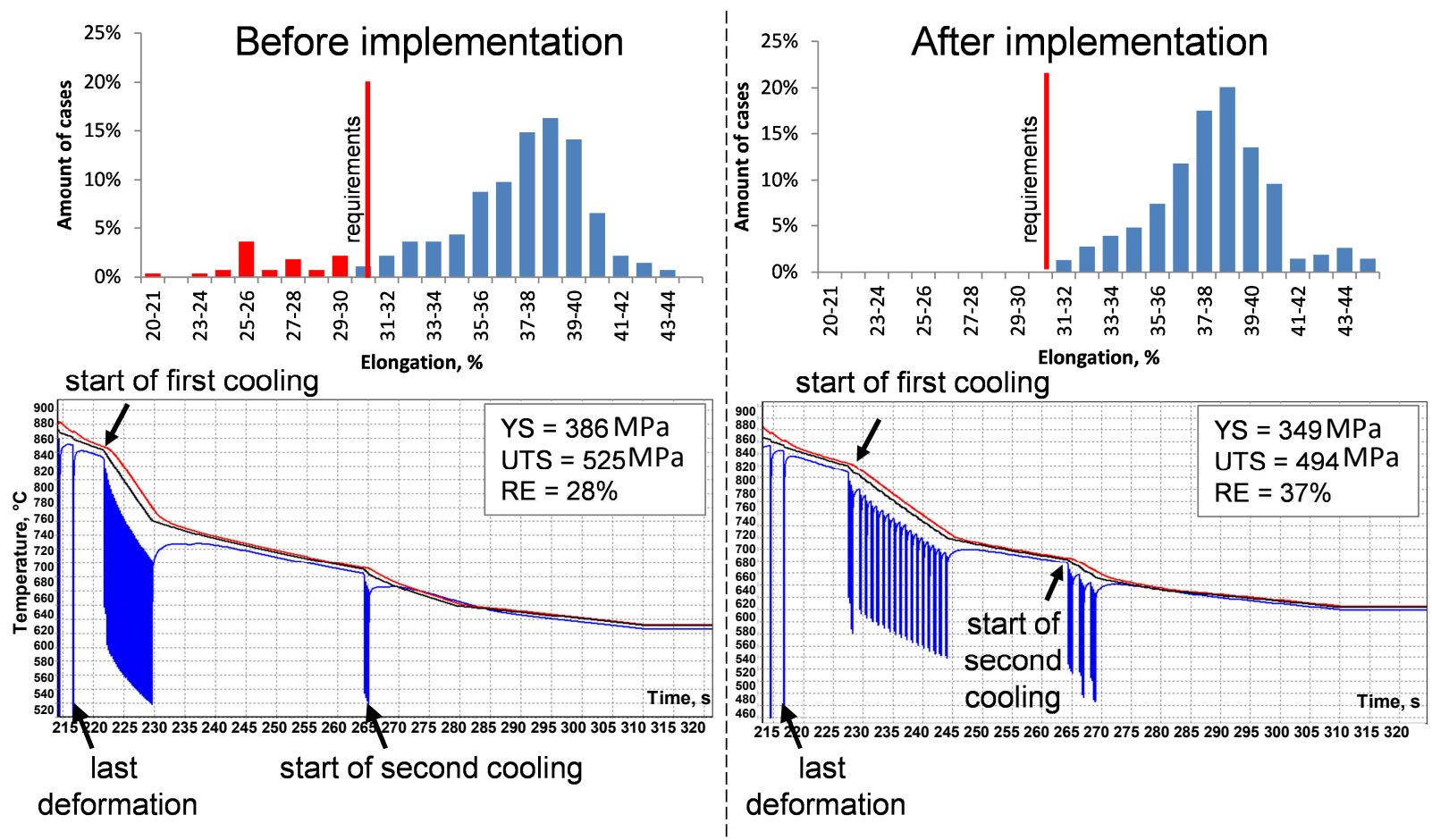

Fig. 7. Practical application of STAN 2000 program for the Grade \#2 (strip $15.3 \times 1480 \mathrm{~mm}$ )

The program STAN 2000 was applied for lifting some limitations on the rolling speed while preserving the mechanical properties (Fig. 8).
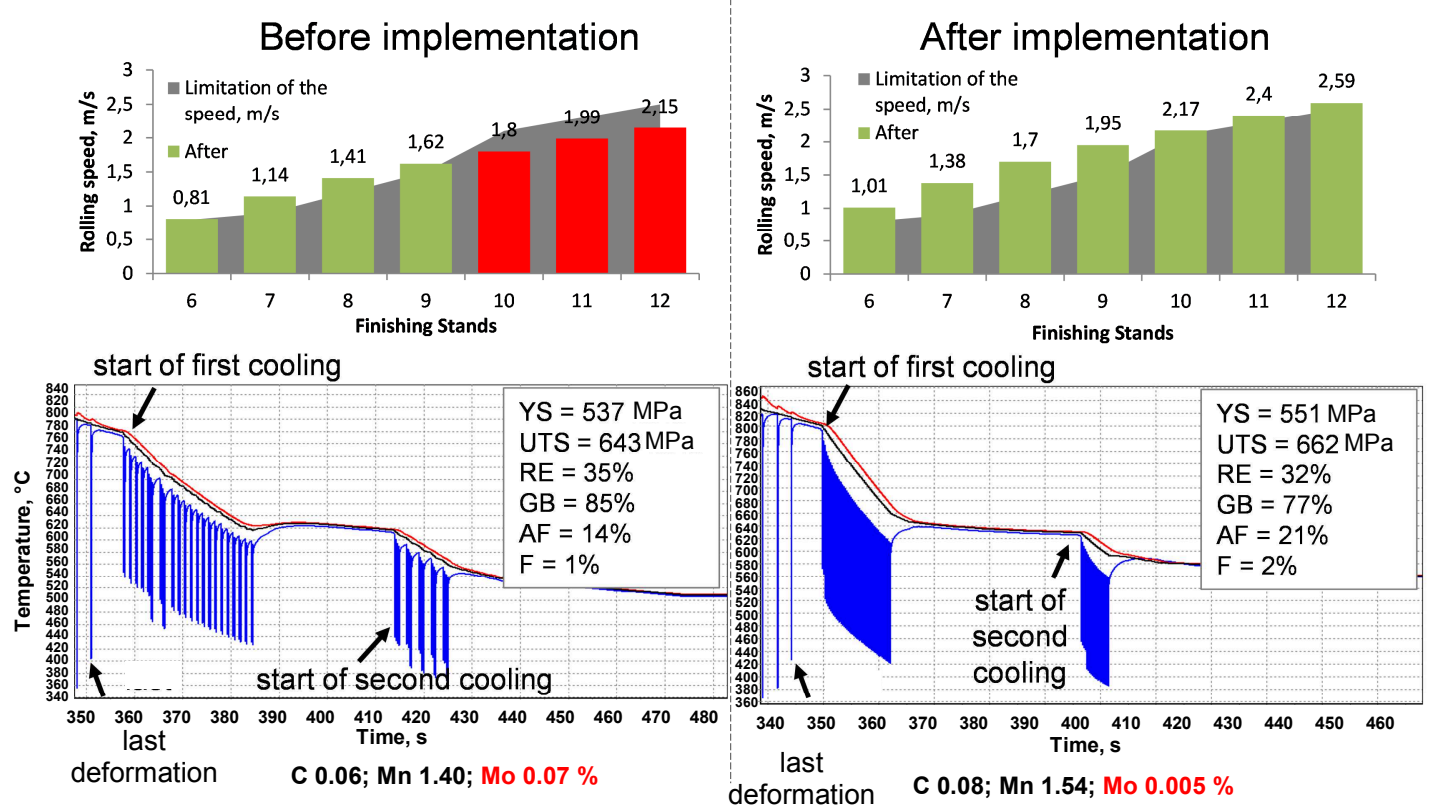

Fig. 8. Practical application of STAN 2000 program for the Grade \#3 (strip 14.4 x $1720 \mathrm{~mm}$ ).

\section{Summary}

An integral computer model STAN 2000 for simulation of steels hot rolling on mill 2000 of SEVERSTAL was developed. The model is widely used in industrial strip production on mill 2000 of SEVERSTAL for working out new and optimizing existing hot rolling and accelerated cooling regimes. The model STAN 2000 has greatly contributed to the development of new technologies for production of pipe steels, high strength steels for mechanical engineering and shipbuilding, as well as a number of structural steels. Utilization of the developed program has significantly reduced the time and costs for optimization of current rolling regimes and for development a new ones. For 
example, the enhanced use of this program by SEVERSTAL brought economic benefits amounting to more than 50 million roubles.

\section{References}

[1] Shulkosky R., Rosburg D., Chapman J., Barnes K. A Microstructure Evolution Model Used For Hot Strip Rolling. Conf. Proc. Materials Science \& Technology, 2003, p.1-17

[2] Andorfer J., Hribernig G., Samoilov A., Luger A., Zeindl J., Rendl K., Stiaszny K. Properties of Hot Rolled Strip Obtained by Calculation or Testing - A Critical Comparison. ECNDT, 2006, p.1

[3] Vasilyev A., Rudskoy A., Kolbasnikov N., Sokolov S., Sokolov D. Physical and Mathematical Modeling of Austenite Microstructure Evolution Processes Developing in Line-pipe Steels under Hot Rolling. Materials Science Forum, 2012, Vols.706-709, pp.2836-2841

[4] Vasilyev A., Sokolov D., Kolbasnikov N., Sokolov S. Modeling of the $\gamma \rightarrow \alpha$ Transformation in Steels. Physics of the Solid State, 2012, Vol. 54, No. 8, pp.1669-1680

[5] Sokolov D., Ogoltcov A., Vasilyev A., Kolbasnikov N., Sokolov S. Modeling of Microstructure and Mechanical Properties of Hot Rolled Steels. Materials Science Forum, 2013, Vol.762, pp.116-121

[6] Sokolov D., Vasilyev A., Ogoltcov A., Sokolov S., Kolbasnikov N. Modeling Mechanical Properties of Steels with Complex Microstructure. In METAL 2014: 23rd Int. Conference on Metallurgy and Materials. Ostrava: TANGER, 2014, p. 58 (DOI: 10.13140/2.1.5116.4488) 